\section{Report of a new case and clinical delineation of mosaic trisomy 9 syndrome}

SUMMARY A newborn girl with trisomy 9 mosaicism is reported. Clinical findings included major malformations: bilateral hip dislocation, dislocation of the left knee, extreme micrognathia, and microsomy. Up to date, 11 liveborn infants with trisomy 9 have been reported, which allows us to make a karyotype/phenotype correlation. Minimal clinical diagnostic criteria are defined, on the basis of which the presence of this syndrome can be suspected.

Since the first liveborn case of trisomy 9 was described in $1973,{ }^{1}$ another 10 cases have been reported. ${ }^{2-10}$ All but two patients were mosaic, although in both cases of full trisomy only one tissue was studied. We wish to report another patient with trisomy 9 mosaicism and, by reviewing the literature, to define this syndrome clinically.

\section{Case report}

A female infant was born at term to a 24-year-old woman and her 27-year-old husband, after a normal spontaneous delivery. The parents were non-

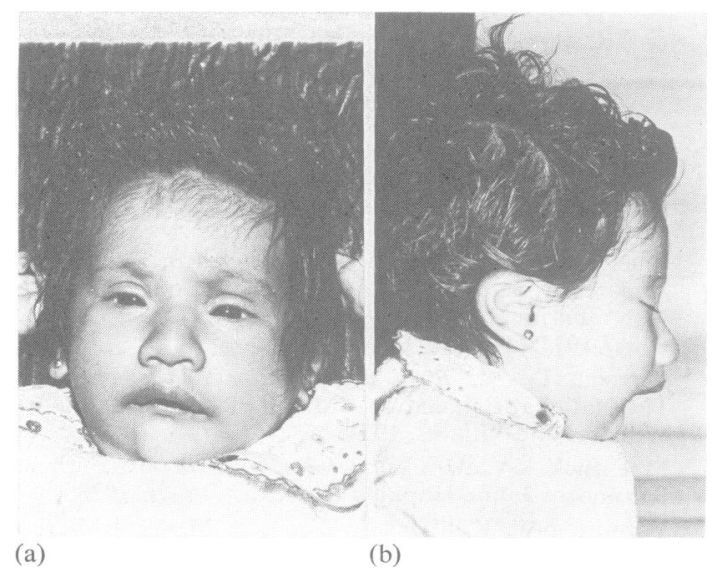

FIG 1 The proband. (a) Note enophthalmus, hypertelorism, small palpebral fissures, prominent nose, and carp-shaped mouth. (b) Note prominent bridge and tip of the nose, upward slanted palpebral fissure, low set, rotated, and malformed ear, and extreme micrognathia.

Received for publication 25 January 1982 consanguineous. The mother had taken contraceptives for 4 months before pregnancy. The pregnancy was normal, although the woman noted that fetal movements were few and feeble.

The proband was referred to us for genetic evaluation at 52 days of age. Physical examination showed: weight $2800 \mathrm{~g}$, height $46 \mathrm{~cm}$, and head circumference $33.5 \mathrm{~cm}$. The patient was hypotonic and had difficulty in sucking. The craniofacial features included (fig 1): microcephaly, $2 \times 2 \mathrm{~cm}$ anterior fontanelle, open sutures, narrow temples, forehead covered by fine hair, hypertelorism, enophthalmus, and small and slightly upward slanting palpebral fissures. The nose was broad and prominent with a bulbous tip, and carp-shaped mouth, high palate, and marked micrognathia were also observed. The ears were almost triangular in shape and were low set and posteriorly rotated; the superior part of the helix was almost horizontal and folded over the antihelix, which was prominent. The neck was short. No external abnormalities were seen in the thorax, abdomen, or external genitalia and the heart was normal. The hands were striking (fig 2) with bilateral simian creases and deep furrows that gave a 'capitonné' aspect to the palms.

Bilateral hip and right knee dislocation were observed. The soles of the feet (fig 3) showed deep furrows and a peculiar groove which began in the first interdigital space, progressed longitudinally, and then turned to the external edge of the feet.

\section{DERMATOGLYPHS}

On the right hand the atd angle was $65^{\circ}$, there was no $c$ triradius, and the palmar axial triradius was in the $t^{\prime \prime}$ position. On the fingers were four whorls and one ulnar loop. On the left hand the atd angle was $60^{\circ}$, the palmar axial triradius was in the $t^{\prime \prime}$ position, and the fingers had three whorls, one arch, and one ulnar loop.

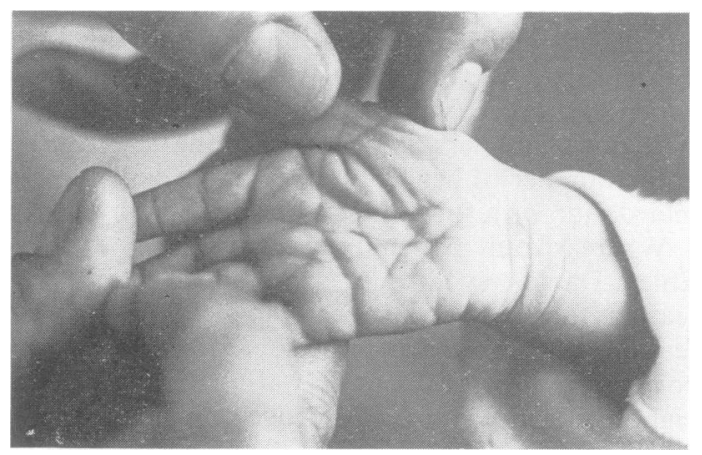

FIG 2 'Capitonne' aspect of the palm and deep transverse groove. 


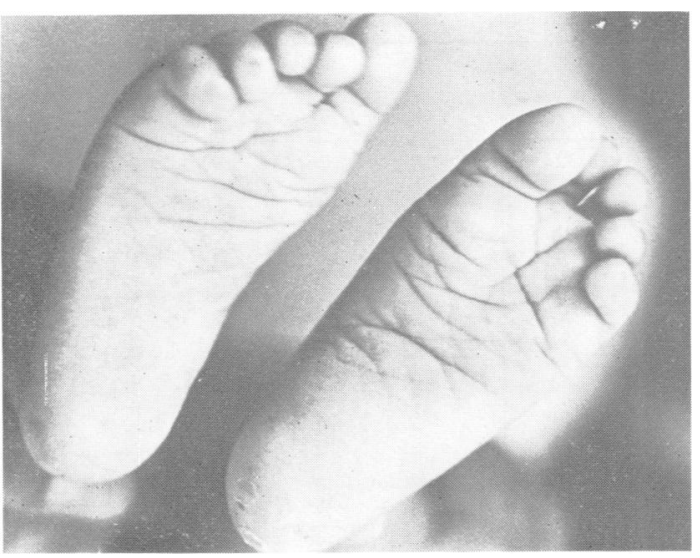

FIG 3 The feet, with deep grooves and a groove from the first interdigital space to the external edge of the feet.

\section{CYTOGENETICS}

Lymphocytes from peripheral blood were cultured by standard techniques. Of the 25 cells analysed, 18 had 46 chromosomes and seven had 47 chromosomes. By means of $\mathrm{G}^{11}$ and $\mathrm{C}$ banding ${ }^{12}$ it was demonstrated that the extra chromosome was a number 9 (fig 4). Thus, the karyotype of the proband was $46, \mathrm{XX} / 47, \mathrm{XX},+9$.

The proband's three chromosomes 9 differed in the size of the qh region: one small $(\mathrm{S})$, one inter-
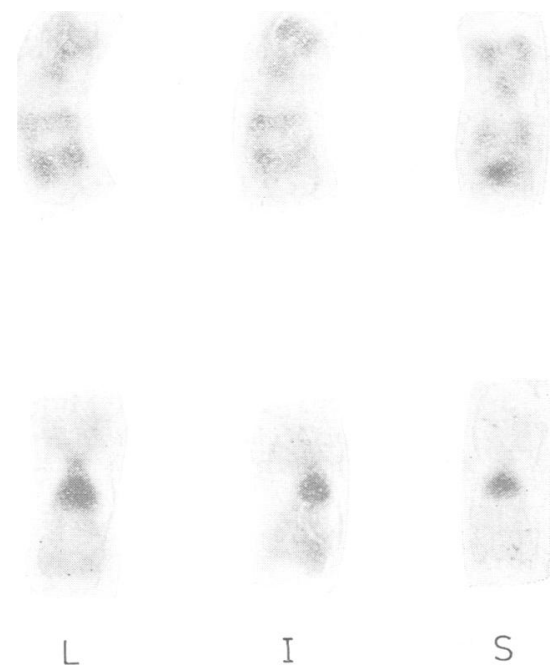

FIG 4 Patient's $G$ and $C$ banded chromosomes 9. Note the differences in the size of the qh regions. mediate (I), and one large (L). The euploid line had an (S) and an (I) segment.

The parental karyotypes were normal. The mother had one chromosome 9 with an (S) qh and one with an (I) qh, while the father had an (I) and an (L) segment. Therefore, it was not possible to determine if the extra chromosome was of maternal or paternal origin.

\section{Discussion}

Two cases were excluded from our review because they showed only partial trisomy 9 . In the patient of Mace et $a l^{13}$ the identification of the distal portion of the long arm of the extra chromosome was uncertain and patient 1 of Sutherland et $a l^{6}$ had only incomplete trisomy through an unbalanced translocation $(7 ; 9)$.

Including our case, 11 cases have been reported since the paper of Feingold and Atkins, ${ }^{1}$ and after a comparative analysis of the phenotypes we concluded that some manifestations are shared by a large enough number to delineate a syndrome.

The table shows the common clinical features shared by at least $50 \%$ of the probands. Microcephaly was a frequent finding, although since it is usually accompanied by short stature and low weight, it would be more appropriate to say microsomy. Only one patient ${ }^{1}$ showed 'pure' microcephaly $(32.5 \mathrm{~cm})$, having a weight and height within the normal range. On the other hand, the proband of Katayama et $a^{10}$ had macrocephaly $(39 \mathrm{~cm})$, normal weight, and short stature.

Eye anomalies were almost constant (11/12), absent only from the report of Seabright et al. ${ }^{5}$ The position of the palpebral fissures was variable, but malformations of the nose, ears, mouth, and mandible were constant and almost identical in all patients. The external genitalia were found to be normal in all the girls, but the six males had small penis with or without cryptorchidism and hypospadias. Only two cases did not have either psychomotor retardation or hypotonia. ${ }^{56}$

Congenital heart disease was very often present. Only three patients did not show cardiopathy, but since exhaustive examinations were not performed, the presence of undetected minor defects cannot be excluded. In positive cases, ventricular septal defect and persistent ductus arteriosus were the most frequent findings.

For early diagnosis of trisomy 9 syndrome, the examination of joints is of great importance, since seven patients had hip dislocation and four had fixed or dislocated knees and elbows. Other signs are less important, either because they are not so frequent or because they are very variable, for 
TABLE Features of mosaic trisomy 9 syndrome.

\begin{tabular}{|c|c|c|c|c|c|c|c|c|c|c|c|c|c|}
\hline \multirow[t]{2}{*}{ Reference } & \multirow[t]{2}{*}{1} & \multirow[t]{2}{*}{2} & \multirow[t]{2}{*}{3} & \multirow[t]{2}{*}{4} & \multirow[t]{2}{*}{5} & \multirow[t]{2}{*}{6} & \multirow[t]{2}{*}{7} & \multirow[t]{2}{*}{8} & \multicolumn{2}{|l|}{9} & \multirow[t]{2}{*}{10} & \multicolumn{2}{|c|}{ Present case } \\
\hline & & & & & & & & & \multicolumn{2}{|c|}{ (Case 1) (Case 2) } & & & \\
\hline Maternal/paternal age & $24 / 25$ & $32 / 40$ & $17 / 19$ & $21 / 22$ & $24 / 24$ & $28 / 33$ & $28 / 32$ & $26 / 28$ & $?$ & $26 / 33$ & $19 /$ & $24 / 27$ & \\
\hline Gestation & 40 wk & 39 wk & 39 wk & 45 wk & & $38 \mathrm{wk}$ & & $36 \mathrm{wk}$ & $\dot{\mathbf{N}}$ & & $\mathbf{N}$ & & \\
\hline Blood: mosaic/non-mosaic & NM & $\mathbf{M}$ & $\mathbf{M}$ & $\mathbf{M}$ & NM & & & & $\mathbf{M}$ & $\mathbf{M}$ & $\mathbf{M}$ & $\mathbf{M}$ & \\
\hline Age at examination & NB & 9 yr & NB & 3 wk & NB & NB & $5 \mathrm{mth}$ & 6 wk & $10 \mathrm{dy}$ & $7 \frac{1}{2}$ yr & NB & $1 \mathrm{mth}$ & \\
\hline Sex & $\mathbf{M}$ & $\mathbf{M}$ & $\mathbf{M}$ & $\mathbf{M}$ & $\mathbf{F}$ & $\mathbf{M}$ & $\mathbf{F}$ & $\mathbf{F}$ & $\mathbf{F}$ & & $\mathbf{M}$ & $\mathbf{F}$ & \\
\hline Low weight & - & + & + & + & + & + & - & + & + & + & - & + & $9 / 12$ \\
\hline Microcephaly & + & + & \pm & \pm & - & + & + & - & - & - & - & + & $5 / 10$ \\
\hline Abnormal eyes & + & + & $\bar{t}$ & $\bar{t}$ & $?$ & + & + & + & - & + & + & + & $11 / 11$ \\
\hline Abnormal nose & + & + & + & + & $?$ & $?$ & + & + & + & - & + & + & $9 / 10$ \\
\hline Abnormal mouth/mandible & + & + & + & + & + & + & + & + & + & - & + & + & $11 / 12$ \\
\hline Abnormal ears & + & + & + & + & + & + & + & + & + & + & + & + & $11 / 12$ \\
\hline Short and/or webbed neck & + & $?$ & - & + & - & - & - & + & + & - & + & + & $7 / 11$ \\
\hline Congenital heart disease & + & + & + & - & + & + & + & + & + & - & + & - & $9 / 12$ \\
\hline Abnormal external genitalia & + & + & + & + & 0 & + & 0 & 0 & 0 & 0 & + & 0 & $6 / 6$ \\
\hline & & & & & & & & & $\begin{array}{l}\text { palmar } \\
\text { creases }\end{array}$ & & & & \\
\hline Abnormal hands/feet & + & - & + & + & + & + & + & + & - & - & - & - & $7 / 12$ \\
\hline Psychomotor retardation & $?$ & + & & + & - & - & + & + & + & + & + & + & $8 / 10$ \\
\hline Age at death & $28 \mathrm{dy}$ & $9 \mathrm{yr}$ & $42 \mathrm{dy}$ & a $9 \frac{1}{2}$ wk & $16 \mathrm{~h}$ & $3 \mathrm{mth}$ & a $5 \mathrm{mth}$ & 12 wk & $10 \mathrm{dy}$ & a $7 \mathrm{yr}$ & $31 \mathrm{~h}$ & $7 \frac{1}{2} \mathrm{mth}$ & \\
\hline
\end{tabular}

+ present; \pm slightly; - absent; ? not known; 0 not applicable; NB newborn; $N$ normal; a still alive

example, abnormalities of the fingers, palmar and sole creases, and metatarsus adductus.

Dermatoglyphic analyses were reported only in the cases of Sutherland et al, ${ }^{6}$ Bowen et al, ${ }^{3}$ Schinzel et $a l,{ }^{4}$ and our case. The results were discordant, but we think that more cases are necessary before assuming that they are not useful.

The mean maternal and paternal ages at the birth of patients with trisomy 9 were $24.6( \pm 4 \cdot 32)$ and $28 \cdot 2( \pm 6 \cdot 18)$, respectively; thus the affected subjects were born to relatively young couples. An exception was a fetus detected in a 40 -year-old woman by prenatal diagnosis.

The mosaicism could be the result of one of the following mechanisms:

(1) Prezygotic non-disjunction producing a trisomic zygote. A further non-disjunction would provoke a line with tetrasomy 9 (not viable) and a persisting euploid line.

(2) Post-zygotic non-disjunction in a euploid zygote. A further non-disjunction would result in a line with monosomy 9 (not viable) and a persisting trisomic line.

Only four of the reported cases showed significant variations in the size of the $9 \mathrm{qh}$ segment and were therefore informative regarding the origin of nondisjunction.

In the cases of Bowen et $a l^{3}$ and Schinzel et $a l^{4}$ a chromosome 9 with a pericentric inversion was present in the mother and in both the proband's euploid and trisomic lines. However, as both authors stated, this finding does not show which of the two above mentioned mechanisms caused the mosaicism. In the case of Seabright et al ${ }^{5}$ both chromosomes 9 of the father had 9qh-, while one of the mother's had an 'intermediate' (I) qh region and the other a 'large' (L) one. In the patient, one chromosome 9 showed a 'small' (S) h segment, another an (I) (apparently from paternal and maternal origin, respectively), and the third one showed a 'very large' segment which the author states was probably the result of an unequal premeiotic interchange in the mother.

In our case, the origin was prezygotic, since the proband had an (S) 9qh like her mother, an (L) like her father, and an (I) that could be of either maternal or paternal origin.

In future cases of trisomy 9 , it is important to study inversions or variations in the size of the $9 \mathrm{qh}$ segment to establish whether non-disjunction arises in maternal or paternal meiosis or post-zygotically.

José María Sánchez, Nora FiJtman, 吕 AND ANa María Migliorini 0 Fundación de Genética Humana, $\underset{\mathrm{C}}{ }$ Salta 661/667, 1074 Buenos Aires, Argentina.

\section{References}

1 Feingold M, Atkins L. A case of trisomy 9. J Med Genet $1973 ; 10: 184-7$.

2 Haslam RHA, Broske SP, Moore CM, Thomas GH, Neill CA. Trisomy 9 mosaicism with multiple congenital anomalies. J Med Genet 1973;10:180-3. 
3 Bowen P, Ying KL, Chung GSH. Trisomy 9 mosaicism in a newborn infant with multiple malformations. $J$ Pediatr 1974;85:95-7.

4 Schinzel A, Hayashi K, Schmid W. Mosaic trisomy and pericentric inversion of chromosome 9 in a malformed boy. Humangenetik 1974;25:171-7.

5 Seabright MA, Gregson N, Mould S. Trisomy 9 associated with an enlarged $9 \mathrm{qh}$ segment in a liveborn. Hum Genet 1976;34:323-5.

6 Sutherland GR, Carter RF, Morris L. Partial and complete trisomy 9: delineation of a trisomy 9 syndrome. Hum Genet 1976;32:133-40.

7 Lewandowski RC, Yunis J. Trisomy 9 mosaicism. Clin Genet 1977;11:306-10.

8 Qazi QH, Masakawa A, Madahar C, Ehrlich R. Trisoniy 9 syndrome. Clin Genet 1977;12:221-6.

9 Tropp MR, Currie M. Mosaic trisomy 9: two additional cases. Hum Genet 1977;38:131-5.

10 Katayama PK, Wilkinson EJ, Herrmann J, Glaspey JC, Agarwal AB, Roesler R, Mattingly R. Clinical delineation of trisomy 9 syndrome. Obstet Gynecol 1980;56: 665-8.

11 Seabright MA. A rapid banding technique for human chromosomes. Lancet 1971 ;ii:971-2.

12 Arrigh:i FE, Hsu TC. Localization of heterochromatin in human chromosomes. Cytogenetics 1974;10:81-6.

13 Mace SE, Macintyre MN, Turk KB, Johnson WE. The trisomy 9 syndrome: multiple congenital anomalies and unusual pathological findings. J Pediatr 1978;92:446-8.

Requests for reprints to Dr J M Sánchez, Fundación de Genética Humana, Salta 661/667, 1074 Buenos Aires, Argentina.

\section{Note}

After this report was submitted for publication, $\mathrm{Dr}$ M Seabright (personal communication) found full trisomy 9 syndrome by prenatal diagnosis in a fetus of a woman aged 42 years.

\section{The hypertelorism microtia clefting syndrome}

SUMMARY A single case of the hypertelorism microtia clefting (HMC) syndrome, a rare autosomal recessive condition, is reported.

Since the original report by Bixler et al ${ }^{1}$ of two sibs with hypertelorism, cleft lip and palate, and microtia, there have been few reports of the syndrome. Identical twins were documented by Schweckendiek et $a l^{2}$ but the syndrome has not yet emerged from being a 'provisional private syndrome'. Other cases are needed to establish the condition as important for the geneticist. The purpose of this paper is to atd a case to the sparse literature.

\section{Case report}

The proband, now one month old, was the product of an uneventful pregnancy. He was delivered at Received for publication 6 February 1982

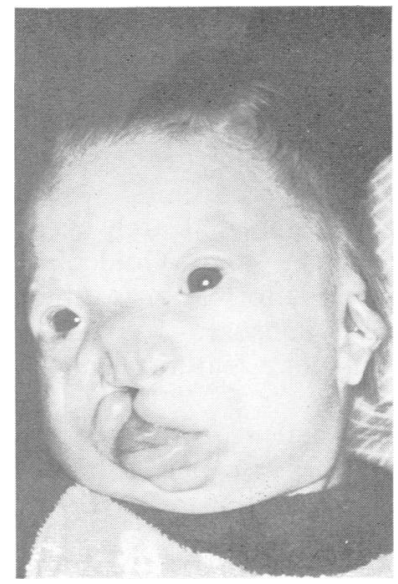

FIGURE The proband at one month.

$38 \frac{1}{2}$ weeks and at birth he was seen to have a unilateral left-sided cleft lip, a cleft palate, a naevus centrally placed on his face (which was fading at one month), gross hypertelorism, narrow palpebral fissures, and a broad bifid nose (figure). Both pinnae were malformed and the external meati were stenosed. At one month he was clearly able to see. There was no cardiac murmur and the renal tract appeared normal. At 2 months he was behaving in a way appropriate for age.

\section{Discussion}

The two sisters described by Bixler et al ${ }^{1}$ had in addition to hypertelorism, microtia, and clefting, cardiac defects, mild retardation, and renal anomalies. Both sisters were below the 3 rd centile for height and were mildly microcephalic. One had a bifid nose and the other a broad nasal tip. The ears were small and deformed and, in particular, the tragus and anterior-superior helix were abnormal in shape. The external auditory meati were absent and inner ear malformations occurred in both. The cardiac defects were an abnormality of the endocardial cushion in one and an ASD in the other. However, other members in this family also had cardiac defects, making interpretation difficult. The renal anomalies were mild, consisting of a pelvic kidney and crossed ectopia.

In the infant reported in this communication, hypertelorism was marked. As with the sisters described by Bixler et $a l^{1}$ the nose was broad and bifid and the cleft lip and palate was unilateral. The malformation of the ears involved the whole of the pinna but especially the helix. It was too early to 